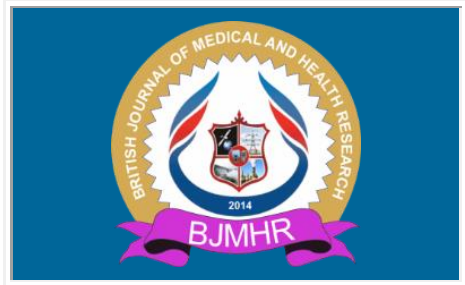

\title{
BJMHR
}

British Journal of Medical and Health Research

Journal home page: www.bjmhr.com

\section{Studies On The Anticancer Activities Of Folic Acid In Combination with Multivitamins In Colon Cancer Rats Induced by Azoxymethane}

\author{
Osama Abdulrahman Shaikhomar \\ Department of physiology, Faculty of Medicine, Umm Al-Qura University, Makkah, KSA.
}

\begin{abstract}
Colorectal cancer one of the mostly found cancer in all over the world. Mortality rate by this cancer is high compared to other types $\mathrm{O}$ cancers. Early diagnosis of this cancer is required to treat this cancer. Many drugs are being used to treat this disease but they all have many side effects so in study we tried to overcome this issue by treating this cancer with supplements. We used male albino SD rats to conduct this study. We divided the rats into 7 groups in which 4 of them were given Azoxymethane (AOM) to induce the colo-rectal cancer while remaining 3 were kept control. One group with AOM was not given any treatment while 3 received folic acid dose (20,40, and 60) respectively along with Vitamin A, C, and E supplementation. Control groups without AMO were also treated with same doses of folic acid in order to compare the results. Results reveal that Folic acid improved GSH, TAC, Lipid peroxidation and superoxide dismutase levels in the AMO treated groups. These tests were also improved in control groups with folic acid and vitamin supplementation. We conclude that Folic acid is found very affective against the colorectal cancer without harming the natural mechanisms in the body. The aim of this study, to evaluate the preventive and protective measure of different doses of folic acid with normal therapeutic doses of vitamin A, C and $\mathrm{E}$ against azoxymethane induce colon cancer in rat.
\end{abstract}

Keywords: Colon and rectum cancer, Folic acid, Vitamin A, C, and E, Azoxymethane, Superoxide dismutase, GSH, Lipid peroxidation.

*Corresponding Author Email: oashaikhomar@uqu.edu.sa Received 10 October 2020, Accepted 03 November 2020

Please cite this article as: Shaikhomar OA., Studies On The Anticancer Activities Of Folic Acid In Combination with Multivitamins In Colon Cancer Rats Induced by Azoxymethane. British Journal of Medical and Health Research 2020. 


\section{INTRODUCTION}

Cancers of gut, specially the colon and rectum cancer are the third most common type of cancers worldwide ${ }^{1,2}$. Cancer of the colon is more frequent than rectal cancer: in industrialized countries, the ratio of colon to rectum cases is 2:1 or more (rather more in females) while in non-industrialized countries rates are generally similar. Rates of this cancer increase with industrialization and urbanization. It has been much more common in high income countries but it is now increasing in middle and low-income countries. Colon cancer affects millions of people worldwide indicating a global health burden ${ }^{3}$. The rate of colon cancer incidence in Western countries is higher than developing countries, these observations suggest that changes in diet and lifestyle might contribute to the incidence of colon cancer ${ }^{4-6}$. Among dietary factors, vitamins $\mathrm{A}, \mathrm{C}$, and $\mathrm{E}$ have been hypothesized to reduce the risk of colon cancer because of their anticarcinogenic properties: vitamin A regulates nuclear receptors that suppress tumor formation, induces cell apoptosis ${ }^{7}$, and enhances immune function ${ }^{8}$ Vitamin $\mathrm{C}$ has antioxidant properties and enhances the immune system $^{9}$ Vitamin $\mathrm{E}$ inhibits lipid peroxidation in cell membranes, prevents oxidative damage of DNA by scavenging free radicals, and inhibits carcinogen production 10,11 .

Folic acid is a synthetic form of the naturally occurring folate that is a water-soluble B vitamin. The active metabolite of folic acid is 5-methyltetrahydrofolate. Folate is the most essential constituent for the biosynthesis, repair, and methylation of DNA. Folates donate one-carbon moieties in order to maintain the stability of DNA. High folate status is associated with a decreased risk of certain human malignancies, including colorectal cancer ${ }^{12,13}$ Several studies have reported that dietary folate protects against the development of colon cancer in colon carcinogenic-treated animals ${ }^{14-16}$. Numerous studies have indicated that under conditions of low dietary intake of folate, results in decreased intracellular 5, 10-methylenetetrahydrofolate, which retards conversion of dUMP to dTMP, leading to cellular thymidine depletion, chromosomal breakage, and malignant transformation ${ }^{17,18,}$ As well as DNA hypomethylation, a leading cause of mutagenesis and abnormal expression of oncogenes, which have been implicated in different types of carcinogenesis including colon cancer ${ }^{19-22}$ However disturbingly, recent data indicate that an excessive intake of folic acid may increase human cancers, including colon, prostate, and breast, by accelerating growth of precancerous lesions, but the dose and timing of such intervention is critical ${ }^{22-26}$ Unfortunately, the protective measure of folic acid to colon cancer is equivocal. Al-Numair ${ }^{27}$ studied the supplementation of folic acid in fed 2, 8 or $40 \mathrm{mg}$ per kg of supplemented diets, throughout the eight weeks in rat induction of colon cancer with azoxymethane and folic acid has protective effect against colon cancer in dose dependent. 


\section{MATERIALS AND METHOD}

\section{Experimental animals:}

Male albino rats of Sprague Dawley strain $(n=84)$ were used. All the rats had similar age and weight to minimize differences in their gut microflora. These rats were housed individually in well-aerated cages and fed on basal diet for one week for adaptation, in animal house of Faculty of medical Applied Sciences, Umm Al-Qura University. The basal diet was composed of $12.5 \%$ casein, $10 \%$ of corn oil, $0.2 \%$ choline chloride, $1 \%$ of vitamin mixture, $5 \%$ cellulose, $4 \%$ salt mixture, $22 \%$ sucrose and up to $100 \%$ corn starch $^{28}$. All of these were provided with normal supplementation of Vitamin A, C, and E at a dose of 80 Units, $200 \mathrm{mg}, 100 \mathrm{mg} / \mathrm{Kg}$ diet respectively ${ }^{27,28}$.

\section{Induction of carcinogenesis}

AOM, azoxymethane, was received from Sigma Chemical Co., St Louis, MI, USA. This drug was used to induce the colon carcinoma in rats. The control group did not receive any drug or saline, whereas, the rats in the vehicle group received $1 \mathrm{~mL}$ injection of $0.9 \% \mathrm{NaCl}$ (physiological saline) intraperitoneally, once a week for two weeks. Similar pattern was followed in case of treatment group (i.e. Azoxymethane group) but the rats in the treatment group, i.e. AOM-injected group, were given injections of AOM intraperitoneally that was dissolved in physiological saline AOM was given to each rat in treatment group, at a dose of $15 \mathrm{mg} / \mathrm{kg}$ body weight, once a week for two weeks which means that each rat in a treatment group received $30 \mathrm{mg} / \mathrm{kg}$ body weight of $\mathrm{AOM}^{29}$.

\section{Experimental Design:}

\section{A. Prevention trials of folic acid}

The rats were divided into 7 equal groups (6 rats in each group), the first three groups were control and were fed on basal diet of Vitamin A, C \& E with supplementation of folic acid 20, 40, $60 \mathrm{mg} / \mathrm{kg} . \mathrm{bw}$, respectively. The remaining four groups were treated with AOM. Of these, 1 of them as kept disease control while other groups (5-7) received dietary supplement with Vitamin A, C \& E with folic acid 20, 40, $60 \mathrm{mg} / \mathrm{Kg} . \mathrm{bw}$, respectively for 2 weeks before treating with AOM and continue for another 6 weeks in the following scheme:

Group (1): control with dietary supplemented with folic $20 \mathrm{mg} / \mathrm{Kg}$. bw

Group (2): control with dietary supplemented with folic $40 \mathrm{mg} / \mathrm{Kg}$. bw

Group (3): control with dietary supplemented with folic $60 \mathrm{mg} / \mathrm{Kg}$. bw

Group (4): AOM only (Cancer positive control).

Group (5): $A O M$ with dietary supplemented with folic $20 \mathrm{mg} / \mathrm{Kg}$. bw for 6 weeks

Group (6): $A O M$ with dietary supplemented with folic $40 \mathrm{mg} / \mathrm{Kg}$. bw for 6 weeks

Group (7): $A O M$ with dietary supplemented with folic $60 \mathrm{mg} / \mathrm{Kg}$. bw for 6 weeks 


\section{B. Protective trials of folic acid}

The same scheme of the preventive trials except AOM will be injected with dietary supplemented with Vitamin A, C \& E with folic acid 20, 40, $60 \mathrm{mg} / \mathrm{Kg} . \mathrm{bw}$ for 6 weeks. Necropsy was carried out at the end of experiment. Necropsy of these animals were done immediately as the they were found deceased. After external inspection, gastrointestinal tract was immediately excised and rinsed with ice-cold physiological saline and kept for histological studies

\section{The analysis of colon consists of 3 parts:}

Part I: The colon mucosal layer scrapings of each rat $(\sim 50 \mathrm{mg})$ were immediately homogenized in $1 \mathrm{~mL}$ of $100 \mathrm{mmol} / \mathrm{L}$ potassium phosphate buffer ( $\mathrm{pH}$ 7.2) by a glass-Teflon homogenizer with an ice-cold jacket and centrifuged at $100,000 \mathrm{~g}$ at $4{ }^{\circ} \mathrm{C}$ for $60 \mathrm{~min}$. The resulting supernatant was used for the determination of GSH and total antioxidant capacity (TAC) measurements, lipid peroxidation and super-oxide dismutase.

Part II: Transverse and descending colon for counting number of aberrant crypt foci (ACF) and the number of crypts in each focus will be identified, counted and recorded by methylene blue staining.

Part III: Rectum and sigmoid colon went through the fixation process. They were kept in formalin, Alcohol, xylol and in the last it was embedded in paraffin. Slides were made H\&E staining by cutting the sections of 5 micron with microtome ${ }^{30}$

\section{Antioxidant estimation}

\section{GSH measurements}

$100 \mu \mathrm{L}$ supernatant was collected from each tissue homogenized sample which was transferred to fresh Eppendorf tubes along with $2 \mu \mathrm{L}$ of monochlorobimane $(25 \mathrm{mmol} / \mathrm{L})$ and $2 \mu \mathrm{L}$ of glutathione-S-transferase reagent were added, as provided by a commercial kit (Randox, USA).

\section{TAC measurements}

A colorimetric method using a Randox Assay Kit (Randox Laboratories Ltd, Antrim, UK) was used to measure the TAC. The assay is based on the incubation of samples with 2, 2'-azino-di[3-ethylbenzthiazoline sulphonate].

\section{Lipid peroxidation and superoxide dismutase}

A colorimetric method using a Randox Assay Kit (Cat\#SD125, Randox Laboratories Ltd, Antrim, UK) was used to measure the, lipid peroxidation and superoxide dismutase.

\section{Statistical analysis:}

Using SPSS program version 16 to find-out descriptive results such as mean, standard deviation and percentages, as well as Diet folic acid supplemented group will be evaluated using twofactor independent measures analysis of variance (ANOVA), P-value less than 0.05 is considered statistically significant ${ }^{31}$. 


\section{RESULTS AND DISCUSSION}

Results reveal that folic acid exerts constructive effects on group of rats that were treated after inducing the colon cancer group along with the supplementation of vitamin $\mathrm{A}, \mathrm{C}$ and $\mathrm{E}$. We measured the glutathione levels in the colon and rectum homogenized samples and found that GSH levels significantly dropped in AMO treated group $(8.66 \pm 0.76)$ as compared to the untreated groups (p-value=0.04). The levels of GSH increased in control groups treated with folic acid 20, 40 and $60 \mathrm{mg} / \mathrm{kg}$ as 22.37, 24.22, 25.37 respectively. GSH levels were also improved in diseased group with treatment of folic acid. Increased dose of folic acid improved the concentration of GSH in the tissue. Folic acid, 20, 40, 60mg/kg also amended the TAC of colo-rectal tissues as $0.51,0.69,0.91$ respectively, compared to the untreated group $(0.42)$. Moreover, it was also proved to be affective in control group as it also increased the TAC levels $1.79,1.82,1.88$ in non-diseased group ( $\mathrm{p}$-value $=0.05$ ). On the estimation of Lipid peroxidation, we found that these supplementations have the capacity to reduce the lipid peroxidation in AMO treated group 2.61, 1.98, 1.94 as compared to the control group 2.74. Folic acid also proved to be effective with different concentrations in the non-diseased group as shown in Table 1. Enzymes involved in the oxidative stress may affect in health improvement colo-rectal cancer. We selected the superoxide dismutase in these groups and found that levels of this enzyme were also improved. We fund that concentration of superoxide dismutase was increased gradually with respect to the folic acid dose as $2.25,2.41,2.46$ in $20,40,60 \mathrm{mg} / \mathrm{kg}$ of folic acid respectively ( $\mathrm{p}$-value=0.03). Folic acid was also proved to be effective in nondiseased group as $2.72,2.83,2.98$ in $20,40,60 \mathrm{mg} / \mathrm{kg}$ of folic acid respectively.

Table 1: Concentration of GSH, TAC, Lipid peroxidation, and Superoxide dismutase.

\begin{tabular}{lllllllll}
\hline & $\mathbf{1}$ & $\mathbf{2}$ & $\mathbf{3}$ & $\mathbf{4}$ & $\mathbf{5}$ & $\mathbf{6}$ & $\mathbf{7}$ & $\begin{array}{l}\text { p- } \\
\text { value }\end{array}$ \\
\hline GSH & $22.37 \pm$ & 24.22 & 25.37 & 8.66 & 10.2 & 13.4 & 14.8 & 0.04 \\
& 0.46 & \pm 0.56 & \pm 0.52 & \pm 0.76 & \pm 0.55 & \pm 0.63 & \pm 0.23 & \\
TAC & 1.79 & 1.82 & 1.88 & 0.42 & 0.51 & 0.69 & 0.91 & 0.05 \\
& \pm 0.32 & \pm 0.36 & \pm 0.91 & \pm 0.23 & \pm 0.55 & \pm 0.84 & \pm 0.76 & \\
Lipid & 1.17 & 1.12 & 0.93 & 2.74 & 2.61 & 1.98 & 1.94 & 0.06 \\
Peroxidation & \pm 0.77 & \pm 0.62 & \pm 0.55 & \pm 0.32 & \pm 0.58 & \pm 0.23 & \pm 0.41 & \\
Super-oxide & 2.72 & 2.83 & 2.98 & 2.22 & 2.25 & 2.41 & 2.46 & 0.03 \\
Dismutase & \pm 0.11 & \pm 0.21 & \pm 0.28 & \pm 0.14 & \pm 0.155 & \pm 0.33 & \pm 0.18 & \\
\hline
\end{tabular}

Necroscopy samples of colon were also used for the H \& E staining which shows very dull eosin staining in AMO treated group however the pink color stain increased gradually in AMO groups which were later treated with folic acid $20,40,60 \mathrm{mg} / \mathrm{kg}$ respectively. No consistent increase in eosin staining was found in the non-diseased, folic acid treated group.

\section{CONCLUSION:}

Colon and rectum cancer are one of the most frequently found cancer throughout the world ${ }^{32}$. 
Various treatments are being found to treat this deadly cancer. Many drugs have already been marketed to treat this cancer like nintidanib, mastinib, Napabucasin ${ }^{33}$ but it all of these drugs have their relevant side effects which harm the patients more than it can heal the disease ${ }^{34,35}$, ${ }^{36}$. This disease has been treated with other supplements but no fruitful effect was found ${ }^{37}$. In the current study we used SD rats to induce the colo-rectal cancer with Azoxymethane $(\mathrm{AOM})$ in experimental rats. This is actually induced by depleting the concentration of glutathione (GSH) and by impairing the total antioxidant capacities in these rats. GSH helps in scavenging the reactive oxygen species in the colonic cells. In healthy cells, more than $90 \%$ of the cells contain reduced GSH levels however, only $10 \%$ of them are found in oxidized form. In our study we the depleted as levels were improved with folic acid treatment with increased dose. Total antioxidant capacity and lipid peroxidation were also tested in these groups.

Colorectal cancer also shows decreased levels of antioxidant enzyme so, to prove this we tested the concentration of superoxide dismutase in our treatment and control groups which also showed that the folic acid along with vitamin A, C and E supplementation improved the enzyme levels which ultimately exerts the anti-cancerous effects in the colon and rectal tissues. Combined effects of all of these results showed the positive impact on the damaged cells in colon and rectum. That were healed by increased dose of folic acid and vitamin supplementation. This study provides the basic idea for the treatment of colo-rectal cancer with dietary supplementation. However counter effects of folic acid on colorectal cancer has also been reported ${ }^{38}$. We suggest the use of folic acid with vitamin A, C and E in the diet as it does not show any harmful effects even when increased dose were given to the rats. Mechanism of action of these supplements are also needed to be explored at the molecular level. Further studies are needed to be done to bring this research to the translational levels. Studies are also needed to be done in order to explore the mechanism by which folic acid heals the cancer damage when combine with other supplementations.

\section{ACKNOWLEDGEMENT:}

The author thank the Institute of Scientific Research and Revival of Islam, Umm Al-Qura University, Makkah, Saudi Arabia for funding my research project. Also, to my loving and supportive wife, Hanady: my deepest gratitude and my children: Wesam, Bassam, and Retaj thank you for allowing me time away from you to research and write. Thanks to my parents as well.

\section{REFERENCES}

1. Parkin DM, Whelan SL, Ferlay J, Teppo L, Thomas DB. Cancer incidence in five continents. Lyon: International Agency for Research on Cancer. Vol. VIII. IARC Scient. Publ. No. 155. 2002. 
2. Ferlay J, Bray F, Pisani P, Parkin DM. GLOBOCAN 2002 Cancer Incidence, Mortality and Prevalence Worldwide. IARC CancerBase No. 5, version 2.0. Lyon: IARC Press; 2004.

3. World Cancer Research Fund/American Institute for Cancer Research. Food, Nutrition, Physical Activity, and the Prevention of Cancer: A Global Perspective. Washington, DC: AICR, 2007

4. Ronellenfitsch U, Kyobutungi C, Ott JJ, Paltiel A, Razum O, Schwarzbach M, Winkler $\mathrm{V}$, Becher H. Stomach cancer mortality in two large cohorts of migrants from the former Soviet Union to Israel and Germany: are there implications for prevention. Eur J Gastroenterol Hepatol 2009; 4:409-16

5. Eschbach K, Stimpson JP, Kuo YF, Goodwin JS. Mortality of foreign-born and USborn Hispanic adults at younger ages: a reexamination of recent patterns. Am J Public Health 2007; 7:1297-304

6. Harding S, Rosato M, Teyhan A. Trends in cancer mortality among migrants in England and Wales, 1979-2003. Eur J Cancer 2009; 12:2168-79

7. Niles RM. Vitamin A and cancer. Nutrition. 2000; 16:573-576.

8. Semba RD. Vitamin A and immunity to viral, bacterial and protozoan infections. Proc Nutr Soc. 1999; 58:719-727.

9. Padayatty SJ, Katz A, Wang Y, et al. Vitamin C as an antioxidant: evaluation of its role in disease prevention. J Am Coll Nutr. 2003; 22:18-35.

10. Packer L. Protective role of vitamin E in biological systems. Am J Clin Nutr. 1991;53:1050S-1055S.

11. Kline K, Yu W, Sanders BG. Vitamin E: mechanisms of action as tumor cell growth inhibitors. J Nutr. 2001;131:161S-163S.

12. Giovannucci Epidemiologic studies of folate and colorectal neoplasia: a review. J Nutr 2002;132:2350-5S.

13. Kim YI. Folate and colorectal cancer: an evidence-based critical review. Mol Nutr Food Res 2007;51:267-92.

14. Kim YI, Salomon RN, Graeme-Cook F, Choi SW, Smith DE, Dallal GE, Mason JB. Dietary folate protects against the development of macroscopic colonic neoplasia in a dose responsive manner in rats. Gut 1996;39:732-40

15. Song J, Sohn KJ, Medline A, Ash C, Gallinger S, Kim YI. Chemopreventive effects of dietary folate on intestinal polyps in $\mathrm{Apc}+/-\mathrm{MSH} 2-/-$ mice. Cancer Res 2000;60:3191-99

16. Song J, Medline A, Mason JB, Gallinger S, Kim YI. Effects of dietary folate on intestinal tumorigenesis in the ApcMin mouse. Cancer Res 2000;60:5434-40 
17. Blount BC, Mack MM, Wehr WM. Folate deficiency causes uracil mis incorporation into human DNA and chromosomal breakage: implications for cancer and neuronal damage. Proc Natl Acad Sci U S A 1997; 94:3290-5.

18. Berger SH, Pittman DL, Wyatt MD Uracil in DNA: consequences for carcinogenesis and chemotherapy. Biochem Pharmacol 2008;76:697-706

19. Sibani S, Melnyk S, Pogribny IP, Wang W, Hiou-Tim F, Deng L, Trasler J, James SJ, Rozen R. Studies of methionine cycle intermediates (SAM, SAH), 20. DNA methylation and the impact of folate deficiency on tumor numbers in min mice. Carcinogenesis 2002;23:61-5

20. Goelz SE, Vogelstein B, Hamilton SR, Feinberg AP. Hypomethylation of DNA from benign and malignant human colon neoplasms. Science 1985;228:187-90

21. Baylin SB, Makos M, Wu JJ, Yen RW, de Bustros A, Vertino P, Nelkin BD. Abnormal patterns of DNA methylation in human neoplasia: potential consequences for tumor progression. Cancer Cells 1991;3:382-90

22. Slattery ML, Schaffer D, Edwards SL, Ma KN, Potter JD. Are dietary factors involved in DNA methylation associated with colon cancer? Nutr Cancer 1997;28:52-62

23. Charles D, Ness AR, Campbell D, Smith GD, Hall MH,. Taking folate in pregnancy and risk of maternal breast cancer. BMJ 2004;329:1375-6.

24. Cole BF, Baron JA, Sandler RS, et al, Folic acid for the prevention of colorectal adenomas — a randomized clinical trial. JAMA 2007;297:2351-9.

25. Mason JB, Dickstein A, Jacques PF, et al, A temporal association between folic acid fortification and an increase in colorectal cancer rates may be illuminating important biological principles: a hypothesis. Cancer Epidemiol Biomarkers Prev 2007; 16:13259.

26. Figueiredo JC, Grau MV, Haile RW, et al . Folic acid and risk of prostate cancer: results from a randomised clinical trial. J Natl Cancer Inst 2009; 101:432-5.

27. Redlich CA, Rockwell S, Chung JS, Sikora AG, Kelley M, Mayne ST.Vitamin A inhibits radiation-induced pneumonitis in rats. J Nutr.1998; 128(10):1661-4.

28. Mehri Kadkhodaee, Hossein Khastar, Mahdieh Faghihi, Rana Ghaznavi, and Maryam Zahmatkesh ,Effects of co-supplementation of vitamins $\mathrm{E}$ and $\mathrm{C}$ on gentamicin-induced nephrotoxicity in rat Exp Physiol 200590 (4) 571-576

29. Al-Numair KS, Waly MI, Ali A, Essa MM, Farhat MF, Alsaif MA. Dietary folate protects against azoxymethane-induced aberrant crypt foci development and oxidative stress in rat colon. Exp Biol Med. 2011; 236(9):1005-11.

30. Bancroff JP, Stevenes A and Turner DR Theory and Practice of Histological Techniques, 1990, 3rd ed. Clurechill Livingston, Edinburgh, London. 
31. SPSS, Statistical Package for Social Science, Computer Software, IBM, SPSS Ver. 16.0 in 2008, SPSS Company, London, UK.

32. Bray, F., Ferlay, J., Soerjomataram, I., Siegel, R. L., Torre, L. A., \& Jemal, A. (2018). Global cancer statistics 2018: GLOBOCAN estimates of incidence and mortality worldwide for 36 cancers in 185 countries. CA: a cancer journal for clinicians, 68(6), 394-424.

33. Cassidy, S., \& Syed, B. A. (2017). Colorectal cancer drugs market.

34. Qin, J. J., Yan, L., Zhang, J., \& Zhang, W. D. (2019). STAT3 as a potential therapeutic target in triple negative breast cancer: a systematic review. Journal of Experimental \& Clinical Cancer Research, 38(1), 195.

35. Bakker, E., Guazzelli, A., Krstic-Demonacos, M., Lisanti, M., Sotgia, F., \& Mutti, L. (2017). Current and prospective pharmacotherapies for the treatment of pleural mesothelioma. Expert Opinion on Orphan Drugs, 5(6), 455-465.

36. Greco, S. H., Spencer, K., \& Carpizo, D. R. (2018). The Future Prospect of Targeted Therapy in Hepatocellular Carcinoma. In Precision Molecular Pathology of Liver Cancer (pp. 235-262). Springer, Cham.

37. Andersen, V., Halekoh, U., Bohn, T., Tjønneland, A., Vogel, U., \& Kopp, T. I. (2019). No Interaction between Polymorphisms Related to Vitamin A Metabolism and Vitamin A Intake in Relation to Colorectal Cancer in a Prospective Danish Cohort. Nutrients, 11(6), 1428.

38. Moazzen, S., Dolatkhah, R., Tabrizi, J. S., Shaarbafi, J., Alizadeh, B. Z., de Bock, G. H., \& Dastgiri, S. (2018). Folic acid intake and folate status and colorectal cancer risk: A systematic Review and Meta-Analysis. Clinical Nutrition, 37(6), 1926-1934.

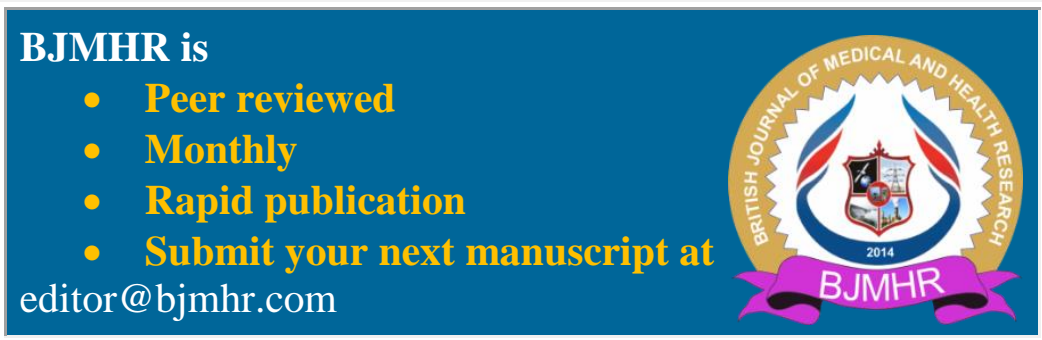

